\title{
Porous titanium substrates coated with a bilayer of bioactive glasses
}

Ana M. Beltrán ${ }^{\mathrm{a}}$, Ana Alcudia ${ }^{\mathrm{b}}$, Belén Begines ${ }^{\mathrm{b}}$, José A. Rodríguez-Ortiz ${ }^{\mathrm{a}}$, Yadir

Torres $^{\mathrm{a}, *}$

a Departamento de Ingeniería y Ciencia de los Materiales y el Transporte, Escuela

Politécnica Superior, Universidad de Sevilla, Virgen de África 7, 41011 Seville, Spain

b Departamento de Química Orgánica y Farmacéutica, Facultad de Farmacia, Universidad de Sevilla, 41012 Seville, Spain

* Corresponding author: ytorres@us.es

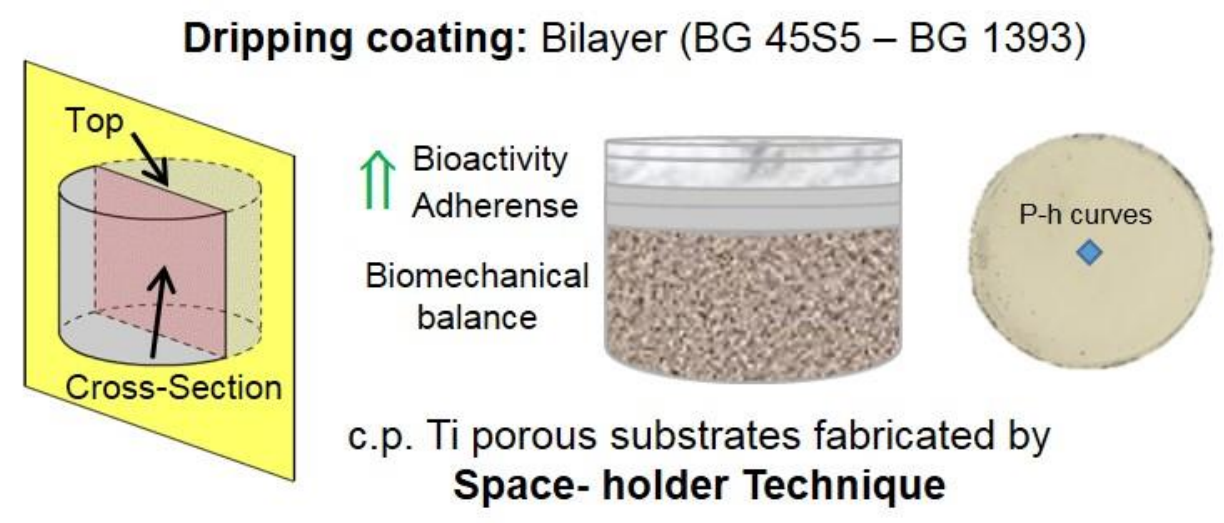

Figure 1: Scheme of a porous Ti substrate fabricated by space-holder technique, coated by the bilayer coating. 

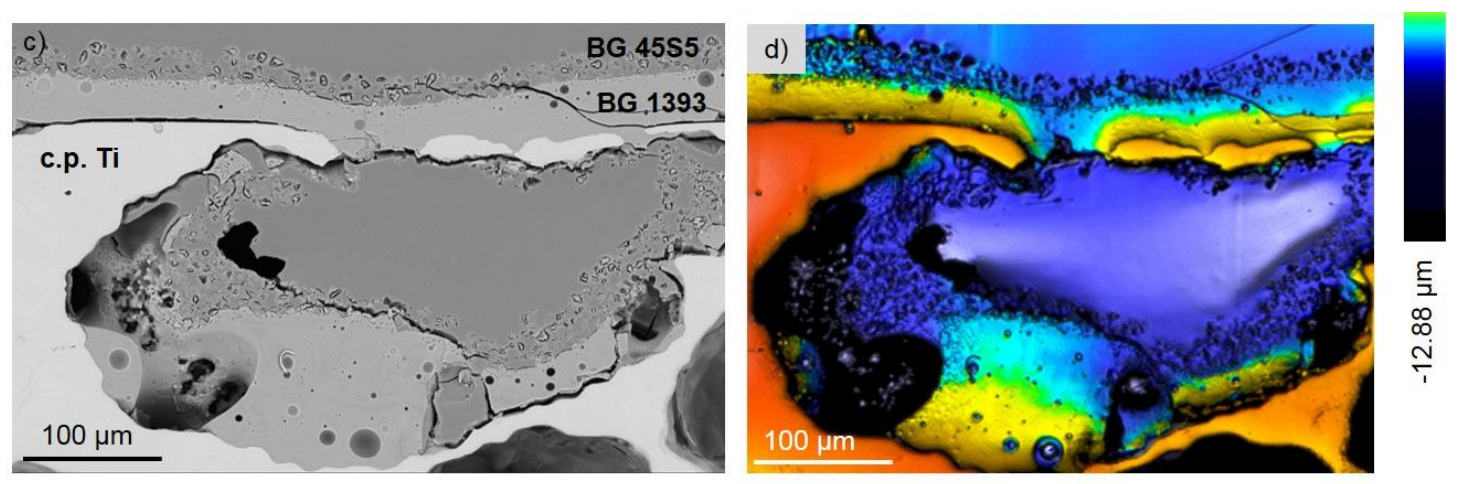

Figure 4: SEM images of the cross-section of the porous c.p. Ti substrates $(a, c)$ and their corresponding confocal images (c,d). (a,b) 30 vol. \%, $100-200 \mu \mathrm{m}$ and (c,d) 60 vol. $\%$ and $355-500 \mu \mathrm{m}$.
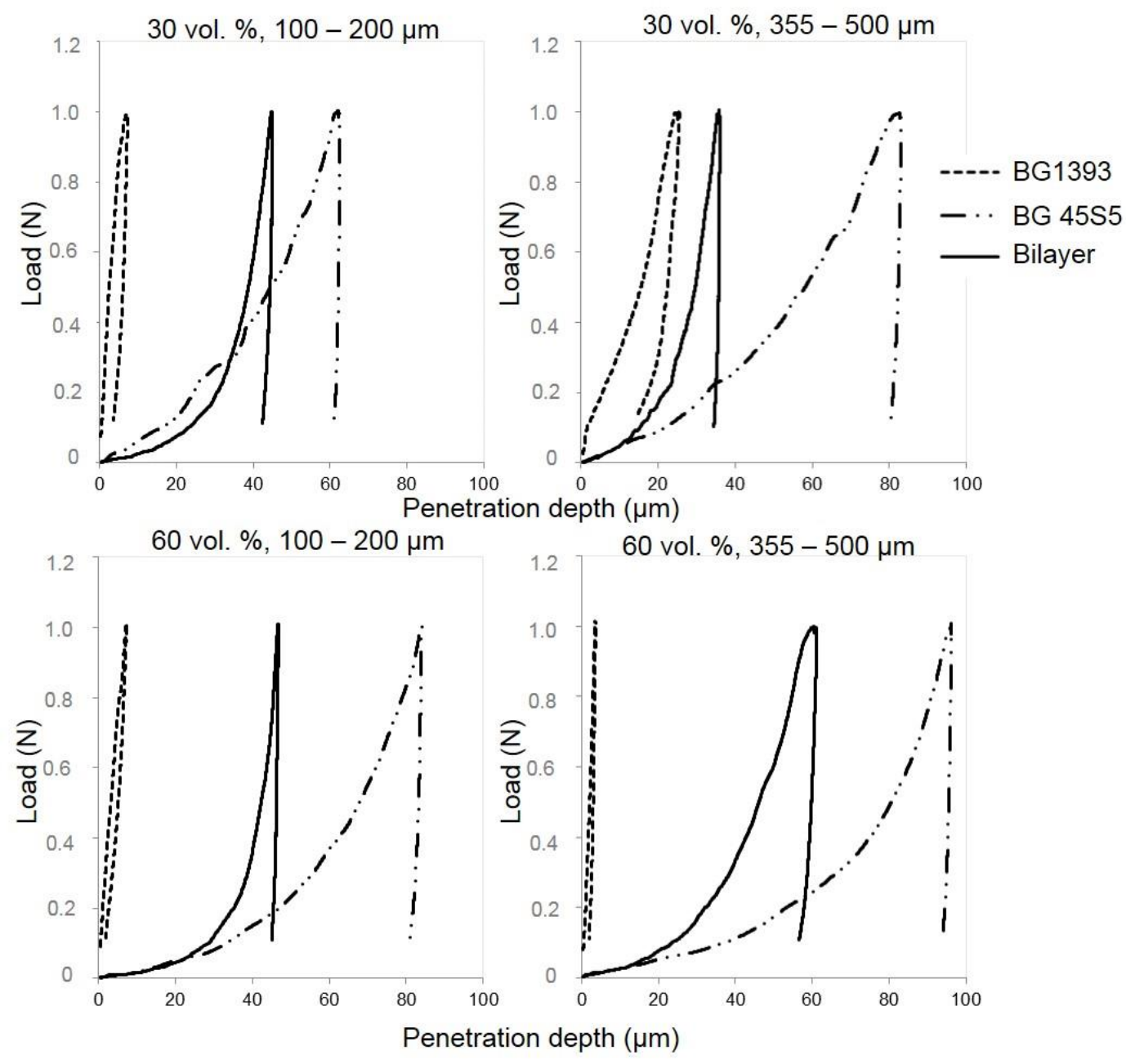

Figure 6. Loading-unloading curves ( $P$ - $h$ curves) of coated (monolayer and bilayer) porous c.p. Ti substrates. 


\section{Conclusions}

In summary, the results obtained in this research work related to the manufacture and characterization of c.p. Ti substrates coated with a novel bilayer BG 1393 - BG 45S5 allow confirming that the space-holder technique is a an effective technique to obtain porous substrates, with a content and pore size range guaranteeing not only the biomechanical (rigidity and mechanical resistance) but also the biofunctional (facilitate infiltration and adhesion of the coating) behavior. the titanium substrate and a greater bioactivity of the BG 45S5 with bone tissue.

\section{Acknowledgments}

This work was supported by the Junta de Andalucía-FEDER (Spain) through the Project Ref. US-1259771 and the project 2004/00001203 (RYC-2004-001497) from M.E.C. (Spain). The authors also thank student J.A. Guardiola for his contribution and laboratory technician J. Pinto for his support in microindentation tests.

\section{References}

[1] I.R. Dental Implants Market Size \& Growth, Dental Implants Market Size, Share \& Trends Analysis Report By Product (Titanium Implants, Zirconium Implants), By Region (North America, Europe, Asia Pacific, Latin America, MEA), And Segment Forecasts, 2018 - 2024, 2018. https://doi.org/10.18637/jss.v042.i08.

[2] C. Palma-Carrió, L. Maestre-Ferrín, D. Peñarrocha-Oltra, M.A. PeñarrochaDiago, M. Peñarrocha-Diago, Risk factors associated with early failure of dental implants. A literature review, Med. Oral Patol. Oral Cir. Bucal. 16 (2011) 2-5. https://doi.org/10.4317/medoral.16.e514. 
[3] A. Solderer, A. Al-Jazrawi, P. Sahrmann, R. Jung, T. Attin, P.R. Schmidlin, Removal of failed dental implants revisited: Questions and answers, Clin. Exp. Dent. Res. 5 (2019) 712-724. https://doi.org/10.1002/cre2.234.

[4] L. Bazli, H.N. Khoramabadi, A.M. Chahardehi, H. Arsad, B. Malekpouri, M.A. Jazi, N. Azizabadi, Journal of Composites and Compounds, 2 (2020) 18-25.

[5] R. López-Píriz, B. Cabal, L. Goyos-Ball, A. Fernández, J.F. Bartolomé, J.S. Moya, R. Torrecillas, Current state-of-the-art and future perspectives of the three main modern implant-dentistry concerns: Aesthetic requirements, mechanical properties, and peri-implantitis prevention, J. Biomed. Mater. Res. Part A. 107 (2019) 1466-1475. https://doi.org/10.1002/jbm.a.36661.

[20] X. Liu, M.N. Rahaman, Q. Fu, A.P. Tomsia, Porous and strong bioactive glass (13-93) scaffolds prepared by unidirectional freezing of camphene-based suspensions, Acta Biomater. 8 (2012) 415-423. https://doi.org/10.1016/j.actbio.2011.07.034.

[21] F. Baino, S. Hamzehlou, S. Kargozar, Bioactive Glasses: Where Are We and Where Are We Going?, J. Funct. Biomater. 9 (2018) 25. https://doi.org/10.3390/jfb9010025.

[22] D. Bellucci, V. Cannillo, A. Sola, Coefficient of thermal expansion of bioactive glasses: Available literature data and analytical equation estimates, Ceram. Int. 37 (2011) 2963-2972. https://doi.org/10.1016/j.ceramint.2011.05.048.

[26] Y. Torres, S. Lascano, J. Bris, J. Pavón, J.A. Rodriguez, Development of porous titanium for biomedical applications: A comparison between loose sintering and space-holder techniques, Mater. Sci. Eng. C. 37 (2014) 148-155. https://doi.org/10.1016/j.msec.2013.11.036. 
[27] S. Muñoz, J. Pavón, J.A. Rodríguez-Ortiz, A. Civantos, J.P. Allain, Y. Torres, On the influence of space holder in the development of porous titanium implants: Mechanical, computational and biological evaluation, Mater. Charact. 108 (2015) 68-78. https://doi.org/10.1016/j.matchar.2015.08.019.

[28] S. Lascano, C. Arévalo, I. Montealegre-Melendez, S. Muñoz, J.A. RodriguezOrtiz, P. Trueba, Y. Torres, Porous titanium for biomedical applications: Evaluation of the conventional powder metallurgy frontier and space-holder technique, Appl. Sci. 9 (2019). https://doi.org/10.3390/app9050982.

[29] Y. Torres, P. Trueba, J. Pavón, I. Montealegre, J.A. Rodríguez-Ortiz, Designing, processing and characterisation of titanium cylinders with graded porosity: An alternative to stress-shielding solutions, Mater. Des. 63 (2014) 316-324. https://doi.org/10.1016/j.matdes.2014.06.012.

[32] H. Eckert, Structural characterization of bioactive glasses by solid state NMR, J. Sol-Gel Sci. Technol. 88 (2018) 263-295. https://doi.org/10.1007/s10971-0184795-7. 